\title{
A integraçáo do processo ensino e aprendizagem de alunas de Terapia Ocupacional e o cuidado de máes de bebês de risco na hospitalização
}

Regina Helena Vitale Torkomian Joaquim, Umaia El-Khatib, Patrícia Carla de Souza Della Barba

Universidade Federal de São Carlos - UFSCar, São Carlos, SP, Brasil.

\begin{abstract}
Resumo: Introdução: Este estudo aborda o processo de ensino e aprendizagem de um grupo de alunas de terapia ocupacional para atuação com mães de bebês de risco no contexto hospitalar. Foi vinculado à atividade de extensão financiada pelo Programa de Extensão Universitária. Objetivo: Teve por objetivo qualificar o grupo para a compreensão do nascimento de risco, da vinculação inicial mãe-bebê no ambiente hospitalar, do acompanhamento do desenvolvimento infantil e para a resolução de problemas, além de ver-se como sujeito de sua própria formação. Método: Participaram seis alunas, três docentes, 26 mães e seus 28 bebês. Os procedimentos se desenvolveram em três eixos articulados: prática, fundamentação teórica e convite à reflexão, orientados, cada eixo, por um dos três docentes. Resultados: Foram realizados 27 encontros de grupo de mães, 11 de supervisões teóricas e 27 de grupo de reflexão. Seis alunas concluíram sua participação no estudo, tendo alcançado qualificação para o atendimento de terapia ocupacional de mães de bebês de risco no ambiente hospitalar e no domicilio após a alta, assim como a corresponsabilização com as pessoas e familiares atendidos. Todas as 26 mães receberam atendimento no berçário; 25 delas, além do berçário, foram atendidas no grupo de mães; e 6, além do berçário e grupo, receberam a visita em domicílio. Conclusão: Este estudo possibilitou contemplar dois sujeitos com a mesma prioridade: a mãe e seu bebê, enquanto sujeitos da atenção de um terapeuta ocupacional, e o aluno, enquanto sujeito da atenção do docente de terapia ocupacional.
\end{abstract}

Palavras-chave: Terapia Ocupacional, Hospitalização, Ensino e Aprendizagem, Recém-nascido Prematuro.

\section{Integrating the teaching-learning process of Occupational Therapy students and the care of mothers of babies at risk during hospitalization}

\begin{abstract}
Introduction: This study approaches the process of teaching-learning of a group of occupational therapy students to act in the care of mothers of babies at risk in the hospital context. It is linked to a community project, supported by the 'Programa de Extensao Universitaria'. Objective: It aimed to qualify the students for understanding the risk rising, the initial mother-baby bond in the hospital environment, the monitoring of the child development and troubleshooting, as well as to see themselves as subjects of their own training. Method: Participants were six students, three teachers, 26 mothers and their 28 babies. The procedures had been developed in three articulated axles: practice, theoretical basis and invitation to reflection, each axle guided by one of three teachers. There were 65 meetings; 27 of the group of mothers, 11 of the group for theoretical overviews and 27 of the reflection group. Six students have completed their participation in the study, having achieved qualification for the care of occupational therapy to mothers of babies at risk during hospitalization and at home after discharge, as well as the co-responsibility with people and served family. All 26 mothers received care in the nursery; 25 of them in addition to the nursery, were treated at mothers group and 6 in addition to the nursery and the group, were visited at home. Conclusion: This study made it possible to contemplate two subjects with the same priority: the mother and her baby, as subjects of the attention and care of an occupational therapist and the student, as the subject of the attention and care of the teacher of occupational therapy.
\end{abstract}

Keywords: Occupational Therapy, Hospitalization, Teaching and Learning, Premature Infant.

Autor para correspondência: Regina Helena Vitale Torkomian Joaquim, Universidade Federal de São Carlos, Rodovia Washington Luís, Km 235, SP-310, CEP 13565-905, São Carlos, SP, Brasil, e-mail: regin@ufscar.br; joaquimrhvt@gmail.com

Recebido em Ago. 18, 2015; 1ª Revisão em Nov. 25, 2015; Aceito em Fev. 23, 2016. 


\section{Introdução}

Uma grande parte das instituiçóes de ensino superior tem historicamente estruturado seus cursos em currículos pautados por disciplinas e no conhecimento compartimentalizado. Dessa maneira, o processo ensino e aprendizagem também tem se restringido à reprodução do conhecimento no qual o professor assume o papel de transmissor de conteúdos e o estudante de seu receptor, num processo no qual a crítica e a reflexão nem sempre são os objetos centrais (CONSELHO..., 2008; MITRE et al., 2008). Esse contexto não necessariamente garante o conhecimento e a construção de uma formação crítica na graduação em saúde.

O desafio de que os profissionais a serem formados na universidade possam construir seu conhecimento de maneira autônoma e significativa tem sido colocado há alguns anos, principalmente, depois da publicação das Diretrizes Curriculares Nacionais para os cursos da área de saúde.

[...] formar um profissional reflexivo, capaz de interagir com o conhecimento de forma autônoma, flexível e criativa é a melhor preparação para a vivência no nosso mundo supercomplexo, incerto, sempre pronto a exigir novos saberes, inspiradores de novas açôes (ALARCÃO, 2003, p. 30).

A educação deve ser capaz de proporcionar a construçáo de redes de mudanças sociais, sendo um dos seus valores principais a crescente busca por métodos que permitam uma prática pedagógica pautada na ética, que seja crítica, reflexiva e transformadora. Considerando-se que a graduação perdura somente alguns anos, enquanto a atividade profissional pode permanecer por décadas, torna-se essencial pensar em uma metodologia para a formaçáo de um profissional ativo, que tenha como foco o aprender a conhecer, o aprender a fazer, o aprender a conviver e o aprender a ser, garantindo a integralidade da atenção à saúde com qualidade, eficiência e resolutividade (MITRE et al., 2008).

Dessa maneira, surgem as metodologias ativas de aprendizagem, alicerçadas em um princípio teórico significativo: a autonomia. No Brasil, essas metodologias se fundamentam nos princípios de Paulo Freire e têm se estruturado como Aprendizagem Baseada em Problemas e Problematização, apontando novas possibilidades no processo de aprendizagem. Essas constituem formas de enfrentamento das rápidas mudanças, da complexidade e da globalização, em que a criatividade e a capacidade de soluçóes originais diante da diversidade se apresentam como condiçóes necessárias aos profissionais (MARIN et al., 2010).

Este estudo parte do currículo implantado no curso de graduação em Terapia Ocupacional da UFSCar que se baseia nas competências que o profissional deve ter ao entrar em contato com sua clientela. Orienta-se por situaçóes reais e simuladas da prática profissional, garante uma aproximação com o mundo do trabalho, valoriza o potencial das açóes observadas e vivenciadas, a fim de formar profissionais terapeutas ocupacionais capazes não só de planejar e gerir serviços, como de construir novos modelos de cuidado, possibilitando a diversificação e a descentralização da formação (BRITO et al., 2007).

O cenário de aprendizagem em que se deu este estudo é o da hospitalização de bebês recém-nascidos de risco, acompanhados de suas mães durante o processo de internaçáo. Está centrado no cuidado da díade mãe-bebê de risco e na integração de alunos graduandos de terapia ocupacional nos contextos de diferentes níveis de ação em saúde - hospitalização e atenção básica.

A combinação desses temas - formação do terapeuta ocupacional em contextos hospitalares, bebês de risco, articulação do trabalho em rede, ainda necessita de estudos no Brasil.

Empenhados na possibilidade de enriquecer o processo de ensino, pesquisa e extensáo acadêmicos, tomamos como questáo de pesquisa como ensinar alunas de terapia ocupacional a atuar com mães no contexto da hospitalização de seus bebês. Nossa hipótese é que a articulação entre 3 eixos de procedimentos (fundamentação teórica, prática vivenciada e autoconhecimento/reflexáo) produz o aprendizado significativo.

\section{Objetivo}

Descrever o processo de ensino e aprendizagem de estudantes de terapia ocupacional para o acompanhamento da díade mãe-bebê de risco, no espaço hospitalar e, após a alta, no domicílio. Especificamente a qualificação do aluno para a compreensão da vinculação positiva inicial mãe-bebê ainda no ambiente hospitalar, para o acompanhamento do desenvolvimento infantil nos primeiros meses de vida, para a proposição de resoluçóes de problemas identificados ou relatados em relação à díade e para ver-se como sujeito de sua própria formação. 


\section{Método}

Este estudo é produto de um projeto de Extensão Universitária aprovado pela Pró-reitora de Extensão da Universidade Federal de São Carlos, vinculado ao Edital Específico do Ministério da Educação e Cultura (MEC) - ProExt 2011. Foi desenvolvido em doze meses, de março de 2012 a fevereiro de 2013.

Participantes: Seis alunas matriculadas regularmente no $3^{\circ}$ ano de graduação do curso de terapia ocupacional, selecionadas mediante os requisitos: manifestação de interesse em participar do estudo, afinidade com o tema, disponibilidade para acompanhar um grupo de mães em internação hospitalar, realizar o seguimento em domicílio e disponibilidade para olhar para si, refletir e transformar-se. Três docentes (A, B e C) do curso de graduação em terapia ocupacional e mães de bebês em internação hospitalar.

Local: Berçário semi-intensivo de uma instituição hospitalar, de uma cidade do interior do Estado de São Paulo e laboratório de pesquisa "Atividade e Desenvolvimento" da Universidade Federal de Sáo Carlos-UFSCar. E ainda os domicílios das mães-bebês acompanhadas no estudo.

Os procedimentos se desenvolveram em três eixos articulados: prática, fundamentação teórica e convite à reflexão, orientados, cada eixo, por um dos três docentes.

1) Prática no hospital/grupo de mães e visita domiciliar: cuidado das mães, escuta, acolhimento.

2) Fundamentação teórica/grupo de supervisão: aproximação e apropriação de fundamentos teóricos relacionados à temática: hospitalização de recém-nascido de risco e desenvolvimento infantil.

3) Grupo de reflexão: abordagem do processo de autoconhecimento e sua articulação com o processo da prática de Terapia Ocupacional.

Esses procedimentos se repetiram semanalmente ao longo do período do estudo e eram todos registrados num único formulário eletrônico de uso coletivo das docentes e alunas. Os registros se davam em sequência a cada procedimento realizado. Ao longo de seu uso, este formulário tornou-se nosso instrumento de acompanhamento e de avaliação dos procedimentos, pelo registro e descrição de cada uma das atividades nos três eixos. Esse modelo de formulário está representado no Tabela 1 abaixo. Também foram gravados e transcritos os encontros do grupo de reflexão.

\subsection{Dinâmica}

Uma vez por semana, as alunas e a docente "A" iam à instituiçáo hospitalar para o contato e realização do grupo de mães. Permaneciam no berçário semi-intensivo, fazendo a escuta e o acolhimento das mães e seus bebês, identificando suas necessidades. Depois desse primeiro contato, as alunas e a docente "A" iam à sala onde o grupo era realizado e dialogavam sobre o que identificaram como necessidade da mãe e, a partir daí, as possibilidades de atividade. Em seguida, a atividade era proposta e realizada.

A partir do grupo de mães, e na sequência, as alunas se reuniam com a docente " $B$ " para a supervisão teórica; elencavam temas e autores que pudessem fundamentar a discussão das ações entre o grupo de alunas. Temas esses mobilizados pela percepção de lacunas ou assuntos que exigiam novas reflexôes e aprofundamentos teóricos. Na sequência da mesma semana, reuniam-se com a docente "C" para a realização do grupo de reflexão, no qual o aluno era convidado ao diálogo e à reflexão acerca das percepçóes pensamentos e sentimentos, mobilizados pelas vivências do grupo de mães e percepções de si considerando seu olhar, seus sentimentos, suas posturas/atitude, em relaçáo a si mesmo, ao outro e ao próprio grupo de reflexão, como estratégia e/ou metodologia de autoconhecimento e aprendizado de terapia ocupacional.

Além disso, um dos desdobramentos do contato realizado com as máes durante o período de internação no berçário ou no grupo de mães era a visita domiciliar. Para que ela acontecesse, havia o agendamento prévio com mãe e familiares, sua concordância e a definição do melhor dia e horário.

\section{Resultados}

\subsection{Quanto ao processo de ensino e aprendizagem}

Os três eixos de procedimento - prática, fundamentação teórica e reflexão - desenvolveram-se de forma articulada, possibilitando a integração e

Tabela 1. Modelo de formulário utilizado - Instrumento de acompanhamento e avaliação de procedimentos.

\begin{tabular}{|c|c|c|c|c|}
\hline $\begin{array}{c}\text { Data e Duração do } \\
\text { grupo }\end{array}$ & Docente & Alunos & $\begin{array}{c}\text { Atividades e } \\
\text { materiais utilizados }\end{array}$ & ados \\
\hline
\end{tabular}


somatória de estratégias de ensino, pois o docente "A", "B" ou "C" estava presente o tempo todo, escutava o aluno o tempo todo e respondia às suas diferentes demandas, no momento em que surgiam.

Para isso, a postura adotada pelo docente era a de colocar de lado a hierarquia do ser docente em relação ao aprendizado do aluno, estabelecendo uma relaçáo horizontal.

O instrumento de acompanhamento e avaliação de procedimentos permitiu que os docentes compartilhassem todas as informaçóes pelos registros, do que havia sido feito, do que necessitava ser feito e seus resultados, permitindo visualizar, assim, a conexão entre as açóes dos docentes e alunos envolvidos. A Figura 1, abaixo, traz a representaçáo gráfica da conexão entre as açóes dos docentes.

No Grupo de mães, desenvolveram-se ações de terapia ocupacional para as mães e bebês no cenário específico da hospitalização. Para essas ações, as alunas deveriam estar no cenário da prática, com seu repertório prévio sobre desenvolvimento infantil e sobre demandas relativas aos recursos da profissão, atividades e sua análise. As alunas aprendiam a estar com as mães, exercitando a escuta, buscando identificar as necessidades do outro. A partir daí, lançavam máo de seus conhecimentos para a proposiçáo de atividades e sua execução. Dessa situaçáo, as alunas identificavam demandas pessoais com relação à sua fundamentação teórica e avaliavam a pertinência de suas percepções sobre a mãe, o bebê, a realização da atividade e sobre o serviço.

Assim, durante o grupo, várias atividades foram feitas, tendo por objetivo:

- Situar as mães em relação ao tempo e espaço vivenciado na internação, já que esse processo naturalmente provoca certa desorientação; um exemplo são as atividades que remetiam a datas comemorativas: na páscoa, confeccionar um cartão para o bebê ou filho que está em casa; no dia das mães, um cartão para elas mesmas ou a quem quisessem presentear; no natal, um cartão de natal e a montagem e decoração da árvore de natal, entre outras.

- Possibilitar a expressão das percepções relacionadas ao contexto vivenciado, como: representação gráfica dos três momentos, gestação (o antes), hospitalização (o agora), a nova família (o futuro); colagem de fotos; bingo de palavras; livro da vida; falar sobre uma foto/figura; redigir uma carta; entre outras.

- Ampliar o repertório, a capacidade do fazer dessas máes, melhorando sua autoestima e autoconfiança, como: pintura em tecido; customizaçáo de caixas; porta-retrato em EVA, entre outras.

É importante destacar que o formato lúdico das atividades foi fundamental, atuando como facilitador na abordagem de conteúdos e situações difíceis, assim como no compartilhamento de informaçóes e orientaçôes.

No grupo de supervisáo, foi levantado o repertório das alunas sobre os temas que consideravam necessários para lidarem com as situaçôes que iriam vivenciar no campo. Os temas elencados foram: relação mãe-bebê e os estudos de Bowlby (1990), Winnicott (1988) e Helen Bee (2003); desenvolvimento do bebê pré-termo e as diferentes características entre o bebê a termo e o prematuro; relação de apego e suas intercorrências (o apego ao prematuro e a incerteza de sua sobrevivência, a condição de ser mãe de um bebê prematuro e a importância da intervenção mediando as relaçóes); percepção da história de

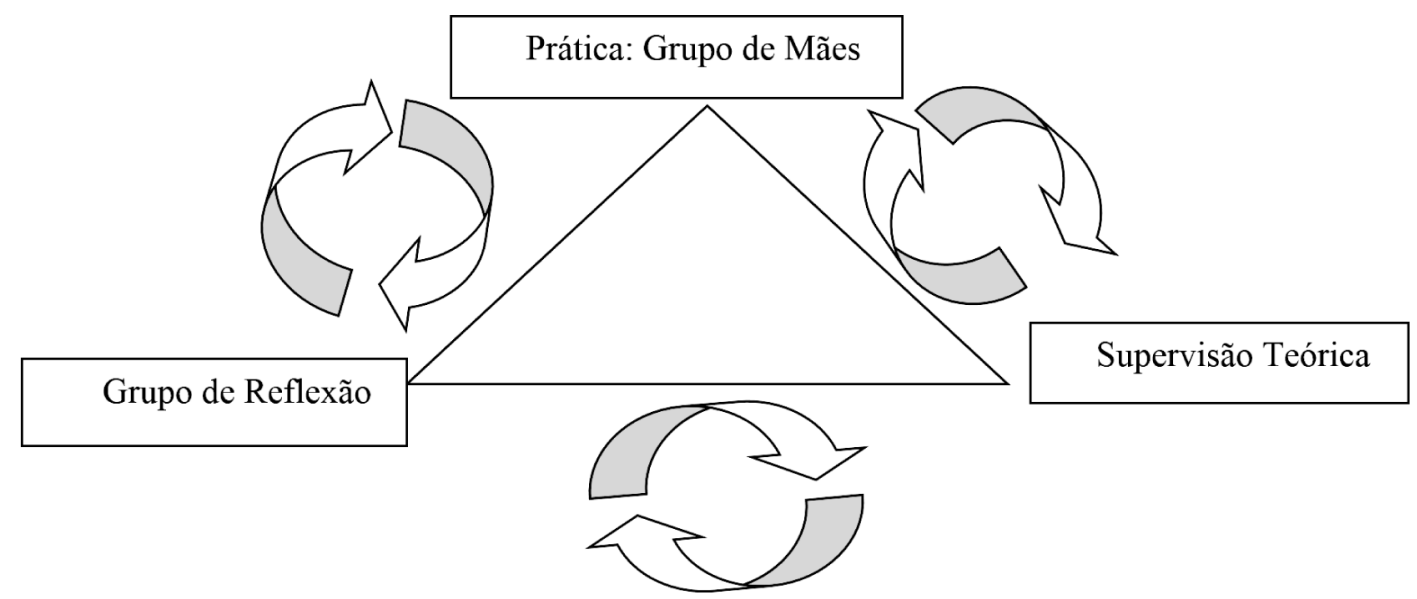

Figura 1. Representação gráfica da conexão entre as ações dos docentes. 
cada família, a estrutura familiar na situação de risco; identificação de fatores de risco (ambientais e biológicos) envolvidos nos casos e o conhecimento sobre o conceito de resiliência; brinquedos e brincadeiras para o bebê; patologias mais frequentes na área da prematuridade e identificaçáo da rede de suporte para a família (comunidade e outros projetos de atenção à criança).

Delimitados os conteúdos teóricos necessários para a compreensão da situação de intervenção junto à população-alvo, foram traçadas as estratégias de estudo no grupo de supervisão, que variaram entre exposição teórica do conteúdo, apresentação de seminários e vídeos, treino em aplicação de protocolos de avaliaçóes, consultorias com docentes da universidade acerca de temas específicos (como patologia) e estudos de caso.

Durante o processo de estudo, a docente responsável e as alunas elencaram questôes de aprendizagem que mobilizaram o aprofundamento em determinadas problemáticas. Os temas foram debatidos com base no referencial teórico, associando-o às situaçôes que estavam vivenciando na prática.

Destacam-se situaçóes que mobilizaram intensa discussão no grupo, como a possibilidade de relacionar o desenvolvimento do bebê pré-termo com a realidade sociocultural das famílias de várias regiōes do município; os riscos ambientais que algumas crianças sofriam ao receberem alta hospitalar, por exemplo, com familiares usuários de álcool e tabaco, e mesmo a reflexáo sobre o contexto complexo no qual essas famílias viviam e o que poderia estar ao alcance do profissional de saúde.

Desta forma, as alunas, mobilizadas por diferentes questôes, tanto no grupo de mães quanto no de supervisão, iam para o grupo de reflexão. No grupo de reflexão, a partir de estratégias articuladas (olhar, sentir, perceber, pensar, colocar-se, indagar-se...), foram pouco a pouco, aderindo ao convite para a reflexão. Também foram usados como recursos a dramatização e a representação com objetos.

De início foram guiadas a perceber a necessidade do outro, a pôr-se em escuta e construir o diálogo centrado no sentimento do outro; o cuidado com as necessidades diferentes por contextos/histórias e momentos diferentes, dessas mães; a necessidade de oferecer o apoio e cuidado através do diálogo e da atividade com todas as mães; e, principalmente, o modo de se conduzir.

No decurso do estudo, vivenciaram de modo intenso o movimento reflexivo, de olhar para o próprio processo de autoconhecimento e de conhecimento de Terapia Ocupacional, apropriando-se do seu agir enquanto terapeuta em formaçáo.
Atenção especial foi dada ao exercício de aprender a olhar, sem julgar e a reconhecer e transformar preconceitos, assim como a identificar possibilidades de mudança de postura, a partir do aprendizado com a atividade e do exercício do sentir e se perceber.

Por meio desses procedimentos, alcançaram a disponibilidade interna para estar para o outro, com a escuta plena. Na presença do óbito, na reflexão da morte e perda, na importância da espiritualidade, no tornar-se mãe e pai, mas principalmente no significado do nascimento. E assim, poder lidar com:

- perceber como vou ao encontro da máe... como está o meu afeto... onde está, aí estou... versus estar para o outro...;

- papel de TO... versus rede de apoio...(estar lá, sentir, acolher, orientar, cuidar, etc.);

- o que está ao nosso alcance...; contexto versus possibilidades pessoais versus demandas e condiçôes do outro.

Foram realizados 27 encontros de grupo de mães, 11 de supervisóes teóricas e 27 de grupo de reflexão. A duração média do grupo de mães foi de três horas, a supervisão teórica levava em torno de uma hora e meia e o grupo de reflexáo três horas.

\subsection{Quanto às alunas (ensino)}

Seis alunas concluíram sua participação no estudo, tendo alcançado:

1) qualificação para o atendimento ocupacional de mães de bebês de risco no ambiente hospitalar e no domicilio após a alta, assim como a corresponsabilização com as pessoas e familiares atendidos;

2) instrumentalização para as açôes de escuta e o acolhimento, daí para a identificação de necessidades e dessa, para a proposição e realização de atividades e avaliaçấo dos resultados;

3) apropriação de sua condição de sujeitos, autores de suas possibilidades de transformação pessoal e profissional.

\subsection{Quanto à atenção às mães (extensão)}

Foram atendidas 26 mães e seus 28 bebês; 15 delas tinham de 13 a 20 anos de idade; e 9, de 30 a 40 anos de idade (2 casos sem informação). A maioria (18) 
delas era casada, apenas 5 eram solteiras (3 casos sem informação).

Todas as 26 receberam atendimento no berçário; 25 delas, além do berçário, foram atendidas no grupo; e 6, além do berçário e grupo, receberam a visita em domicílio. Este total de visitas ao domicílio é decorrência da alta hospitalar, do desejo das mães em receber a visita da aluna e dos imprevistos relativos ao agendamento.

Nessas visitas as mães tornaram-se o foco principal da atenção na medida em que trouxeram como demanda suas angústias quanto: ao cuidado do filho sem o auxílio da equipe; à adequação do ambiente para o bebê; ao afastamento do trabalho e implicaçóes legais; à relação com o parceiro e familiares.

É fundamental ressaltar que na hospitalização a vinculação mãe-bebê tende a ficar em segundo plano, porque a preocupação maior é com a sobrevivência do bebê; não há como evitar a separaçáo física da mãe de seu bebê recém-nascido e, em alguns casos, por longos períodos; a mãe sofre o impedimento de amamentá-lo, tocá-lo, segurá-lo no colo, trocá-lo, banhá-lo, perdendo, nessas situaçôes, suas possibilidades de interagir com seu bebê naturalmente e, mais que isso, perdendo sua autonomia e referência como mãe.

Esse projeto permitiu atuar na formação do vínculo mãe-bebê, favorecida por meio da realização de atividades, como confecção de móbile, cartas para o bebê, construção de ninhos com cueiros, a aproximação da mãe do cotidiano materno apesar do ambiente desfavorável, o hospital, amenizando assim o impacto dessa internação.

\section{Conclusão}

Este estudo possibilitou contemplar dois sujeitos com a mesma prioridade: a mãe e seu bebê, enquanto sujeitos da atenção de um terapeuta ocupacional, e o aluno, enquanto sujeito da atençáo do docente de terapia ocupacional.

Os objetivos foram alcançados e a metodologia se mostrou adequada, atingindo-se os resultados pretendidos.

Acreditamos que as alunas que vivenciaram o projeto tornaram-se capazes de se reconhecerem como profissionais de saúde, cujas açôes não têm apenas consequência sobre o outro, mas também sobre si mesmos, na medida em que a ação do outro repercute igualmente sobre ele, mobilizando-os à busca da modificação do seu próprio desempenho.

\section{Referências}

ALARCÁO, I. Professores reflexivos em uma escola reflexiva. São Paulo: Cortez, 2003.

BEE, H. A criança em desenvolvimento. São Paulo: Artmed, 2003.

BOWLBY, J. Apego. São Paulo: Martins Fontes, 1990.

BRITO, C. M. D. et al. Projeto politico pedagógico do curso de graduação em Terapia Ocupacional. Universidade Federal de São Carlos, 2007. Disponível em: <http:// www.prograd.ufscar.br/projetoped/projeto_TO.pdf>. Acesso em: 1 ago. 2012.

CONSELHO NACIONAL DE SECRETARIAS MUNICIPAIS DE SAÚDE - CONASEMS. A formação de profissionais de saúde em sintonia com o SUS: currículo integrado e disciplinar. Brasília: Núcleo de Gestão do Trabalho e Educação na Saúde do CONASEMS, 2008.

MARIN, M. J. S. et al. Aspectos das fortalezas e fragilidades no uso das metodologias ativas de aprendizagem. Revista Brasileira de Educação Médica, Rio de Janeiro,v. 34, n. 1, p. 13-20, 2010. http://dx.doi. org/10.1590/ S0100-55022010000100003.

MITRE, S. M. et al. Metodologias ativas de ensino e aprendizagem na formaçáo profissional em saúde: debates atuais. Ciência e Saúde Coletiva, Rio de Janeiro, v. 13, p. 2133-2144, 2008. Suplemento 2.

WINNICOTT, D. W. Os bebês e suas mães. São Paulo: Martins Fontes, 1988.

\section{Contribuição dos Autores}

Regina Helena Vitale Torkomian Joaquim, Umaia El-Khatib, Patrícia Carla de Souza Della Barba foram responsáveis pela orientação do trabalho e pelas análises realizadas. Todas as autoras são responsáveis pela redação, revisão do texto e aprovaram a versão final do artigo.

\section{Fonte de Financiamento}

Programa de Extensão Universitária - Secretaria do Ensino Superior - Ministério de Ciência e Tecnologia - PROEXT/SESu/MEC. 